\title{
Toxicity evaluation of reactive dyestuffs, auxiliaries and selected effluents in textile finishing industry to luminescent bacteria Vibrio fischeri
}

\author{
Chunxia Wang ${ }^{\mathrm{a}}$, Ayfer Yediler ${ }^{\mathrm{b}, *}$, Doris Lienert ${ }^{\mathrm{c}}$, Zijian Wang ${ }^{\mathrm{a}}$, \\ Antonius Kettrup b,c \\ ${ }^{\text {a }}$ Research Center for Eco-Environmental Sciences, State Key Laboratory of Environmental Aquatic Chemistry, Chinese Academy of \\ Sciences, Beijing 100085, People's Republic of China \\ ${ }^{\mathrm{b}}$ GSF - National Research Center for Environment and Health, Institute of Ecological Chemistry, Postfach 1129, 85758 Neuherberg, \\ Germany \\ c Technical University of Munich, Chair of Ecological Chemistry, 85350 Freising, Germany
}

Received 17 April 2000; accepted 18 December 2000

\begin{abstract}
The toxicity of 17 selected process effluents, 11 reactive dyestuffs and 8 auxiliaries from a textile dyeing and finishing mill in Ayazaga, Istanbul, Turkey was evaluated by bioluminescence test using bacteria Vibrio fischeri in LUMIStox 300. The $\mathrm{EC}_{20}$ and $\mathrm{EC}_{50}$ for auxiliaries, the $\mathrm{EC}_{20}$ for dyestuffs were determined. For selected process effluents GLvalues, the dilution level at which a wastewater sample causes less than $20 \%$ inhibition, were examined. Our results demonstrate that the toxicity assessment with luminescent bacteria is effective and of practical use for chemicals applied in textile finishing industry with the limitation of the deep dark-colored dye bath samples and for the related effluents. Inhibition effects of numerous dyestuffs as well as auxiliaries to luminescent bacteria differed considerably with a range 5-600 mg $1^{-1}$ for $\mathrm{EC}_{20}$ and 9-6930 $\mathrm{mg}^{-1}$ for $\mathrm{EC}_{50}$, respectively. Among 17 effluents, 1 sample exhibited high toxicity $(\mathrm{GL}=100), 7$ showed moderate toxicity $(\mathrm{GL}=12-32)$, and 9 had a GL-value $<10$ indicating a low or no toxicity. (c) 2002 Elsevier Science Ltd. All rights reserved.
\end{abstract}

Keywords: Bioassay; Bioluminescence test; Textile finishing industry effluents; Dyestuffs; Auxiliaries

\section{Introduction}

The textile finishing industry is an important contributor to many national economies, encompassing both small- and large-scale operations worldwide. Due to the rapid change in customers' demands textile finishing industry is challenged to use high quantities of

\footnotetext{
*Corresponding author. Tel.: +49-089-3187; fax: +49-0893187-3371.

E-mail address: yediler@gsf.de (A. Yediler).
}

dyestuffs and auxiliaries. The total amount of dyestuffs used e.g., in one textile mill in Istanbul, Turkey in 1997 was $143,000 \mathrm{~kg}$. Additionally $677,000 \mathrm{~kg}$ of auxiliaries was consumed in the same mill (Paker, 1999). The textile industry utilizes about 10,000 different dyes and pigments in the world (Spadaro et al., 1994). Over 50\% of all the dyes used in the industry are azo dyes. They contain at least one and up to four azo groups usually attached to two radicals of which at least one but usually both are aromatic groups. The increased use of cotton has additionally led to substantial growth in the usage of reactive dyes. Consequently, the most pressing environmental problem facing the textile industry is related 
to reactive dyes (Lin and Lin, 1993; Zissi and Lyberatos, 1996; Beydilli et al., 1998).

In general, dyestuffs with low biodegradability pass through the wastewater treatment plant and are released into the environment because of their high solubility in water. Their low $\mathrm{BOD}_{5}$ : $\mathrm{COD}$ ratio values (less than 0.1) indicate their resistance to conventional biological treatment. Effluents containing compounds of azo dyes are more recalcitrant towards environment (Lopez et al., 1998). Whenever the harmful effect of textile wastewater is being concerned, reactive dyestuffs are the main point to be focused on because of their toxic potential. In contrary very less is known about the auxiliaries in aquatic environment although the amount of auxiliaries consumed in wet dyeing processes is much higher than dyes (Ince, 1999). Most auxiliary chemicals used in dyeing processes are generally non-reactive and are not absorbed by the substrate being dyed and may cause additional problems on the aquatic environment.

Due to the high cost of conventional animal tests, most of the chemicals involved in the present manufacturing technology have been poorly tested for their toxicity. Literature on reactive azo dyes and especially on auxiliaries to predict their toxicity is very scarce. In order to evaluate the risk to the environment from longterm exposure of azo dyes and auxiliaries from textile dyeing and finishing industry a toxicity test which is time-saving and cost-effective may provide some guidance as a pre-screening test and might be of value in routine monitoring. In this study bioluminescence test was chosen as a reproducible and sensitive screening method to determine overall toxicity from different types of samples obtained from a textile mill nearby Istanbul (Bulich, 1979; Devare and Bahadir, 1994; Galli et al., 1994; Asami et al., 1996; Dombroski et al., 1996; Kahru et al., 1996; Froehner et al., 2000).

Our investigations in this study mainly focus on (1) the assessment of the applicability of bioluminescence test; (2) the evaluation of the toxicity of reactive azo dyes and mostly used auxiliaries, as well as effluents from selected processes of a textile dyeing and finishing industry. We determined two toxic designations, the $\mathrm{EC}_{20^{-}}$and $\mathrm{EC}_{50^{-}}$-values for auxiliaries, $\mathrm{EC}_{20}$-value for synthetic dyestuff solutions, GL-values for selected process effluents and two composite samples. In addition the conventional parameters (TOC, $\mathrm{COD}, \mathrm{pH}$, conductivity) were also measured.

\section{Materials and methods}

All dyestuffs and auxiliaries tested were selected due to their high annual consumption and were courteously provided by a textile dyeing and finishing mill in Ayazaga, Istanbul, Turkey. The selected process effluents were collected in April and June 1999 from the same mill, which is processing cotton and synthetic knit fabrics and their blends.

The acute bioluminescence assay was carried out following standard operational procedures (DIN 38412 L34/L341, Germany and ISO DIS 11348). The kits for conducting the test were purchased from Dr. Bruno Lange $\mathrm{GmbH}$, Berlin, Germany and were used without modifications. All water used was purified using a MilliQ (Millipore, Watford, UK) $(18.2 \mathrm{M} \Omega \mathrm{cm})$. All solvents and chemicals were analytical grade unless stated. The bioluminescence was measured in a luminometer (LUMIStox, Dr. Lange GmbH, Berlin, Germany). Vibrio fischeri is a marine bacterium that requires an environment with an adequate salt content. Therefore, all samples were prepared in aqueous solution containing $2 \% \mathrm{NaCl}$ solution prior to measurement. For wastewater samples, salt concentration was adjusted to $2 \%$ by adding solid $\mathrm{NaCl}$ if necessary. $\mathrm{pH}$ was adjusted to 7.4 by $0.1 \mathrm{~mol}^{-1} \mathrm{NaOH}$ or $0.1 \mathrm{~mol}^{-1} \mathrm{HCl}$. Before start the bacteria were first reactivated and kept in $15 \pm 1^{\circ} \mathrm{C}$. A serial dilution of the samples in LUMIStox diluent $(2 \% \mathrm{w} / \mathrm{v} \mathrm{NaCl})$ was prepared. Care was taken to mix the sample thoroughly at each step. Neat diluent were used as a control (fourfold). The lyophilized bacterial reagent was reconstituted and diluted as specified in the LUMIStox acute toxicity basic test procedure and all vials were allowed to stabilize at $15^{\circ} \mathrm{C}$ for $15 \mathrm{~min}$. Bacterial luminescence was then measured before sample addition ( 0 min reading), and after 15 or $30 \mathrm{~min}$ incubation time, respectively. The decrease in bioluminescence, indicating a toxic effect by the test substance, was measured after 15 min contact time with samples. According to the manufacturers description of the LUMIStox 300, there should not be large differences when exposure times of 5 , 15 and $30 \mathrm{~min}$ are chosen. But when different substances are to be evaluated, it should be tried to use the same incubation time to be able to compare the results.

Analyses were carried out at $15 \pm 1^{\circ} \mathrm{C}$. All samples were tested in duplicates. The inhibition of natural luminescence of photo-bacteria is regarded as the toxicity endpoint. For single chemicals two toxic designations for each sample was utilized namely $\mathrm{EC}_{20}$ and $\mathrm{EC}_{50}$. A concentration required to cause lower than $20 \% \mathrm{EC}$ was scored as non-toxic and higher than $20 \%$ bioluminescence inhibition was scored as toxic. The EC-values were calculated by LUMISsoft version 3.01. GL-values were applied for wastewater samples, most suitable and commonly used, delivering the information for dilution levels at which samples cause less than $20 \%$ inhibition to the luminescent bacteria after certain period of incubation time (15 or $30 \mathrm{~min}$ ).

Since light-absorbent colorants of the samples can distort the results of the luminescent bacteria test, the color correction has to be carried out during the measurement of colored samples. We determined that generally by LUMIStox 300, equipped with color correction 
facility, the measurements deliver reliable results when the optical density of a colored sample is in the extinction range $20-1800 \mathrm{mE}$.

\section{Results and discussion}

In Table 1 the 15 min $\mathrm{EC}_{20}$ - and $\mathrm{EC}_{50}$-values of selected auxiliaries according to their increased toxicity are listed (decreasing $\mathrm{EC}_{50}$ - and $\mathrm{EC}_{20}$-values). Since the relationship between $\mathrm{EC}_{20}$ and $\mathrm{EC}_{50}$ is not linear we decided to give both values presenting two toxic designation for each sample (Backhaus et al., 1997).

The results of $\mathrm{EC}_{50}$ for 8 auxiliaries covered over almost four orders of magnitude. Based on the $15 \mathrm{~min}$ $\mathrm{EC}_{20}$ - and $\mathrm{EC}_{50}$-values, the most toxic auxiliary investigated was "Peristal BFL", a wetting agent, with the 15 $\min \mathrm{EC}_{50}$ of $45 \mathrm{mg} \mathrm{l}^{-1}$. "Setaglesin A", used as dissolvent, can be listed as the auxiliary with the lowest toxic capacity with a $15 \mathrm{~min} \mathrm{EC}_{50}$ of $22.9 \mathrm{mg} \mathrm{l}^{-1}$. For two dispersants, the relative toxicity of "Dispersan PNG" is higher than "Breviol A 69". As a consequence of the acute toxicity measurements obtained for both dispersants, it should be recommended to substitute the Dispersan PNG.

In this study, due to the high optical density $(>1800$ $\mathrm{mE}$ ) of most of the dyes, information on $\mathrm{EC}_{50}$ could not be obtained. In Table 2 the $15 \mathrm{~min} \mathrm{EC}_{20}$-values of reactive dyestuffs tested according to their increased toxicity are listed (decreasing $\mathrm{EC}_{20}$-values).

Only for "Ambifix yellow VRNL" and an acidic dye, "Lanasyn yellow S2GL", EC $_{50}$ could be obtained: the results indicate that they are the most toxic dyes among the 11 reactive azo dyes investigated with an $\mathrm{EC}_{50}$ of 22 and $70 \mathrm{mg}^{-1}$, respectively. Our results also show that for dyestuffs the $\mathrm{EC}_{20}$-values might be a more useful endpoint than $\mathrm{EC}_{50}$ because of the methodical problem caused by their intense color. Dodard et al. (1999) also experienced the same phenomena for some chemicals having a limited water solubility: they also conclude that the information obtained on $\mathrm{EC}_{20}$-value is more reliable

Table 1

$\mathrm{EC}_{20^{-}}$and $\mathrm{EC}_{50}$-values $\left(\mathrm{mg} \mathrm{l}^{-1}\right)$ for auxiliaries used in textile finishing industry obtained by bioluminescence test (15 min)

\begin{tabular}{llrr}
\hline Auxiliaries & Comment & $\mathrm{EC}_{50}$ & $\mathrm{EC}_{20}$ \\
\hline Setaglesin A & Dissolvent & 22,910 & 6930 \\
Mollan 129 & Ion acceptor & 15,030 & 2580 \\
Detergent X & Detergent & 7760 & 1970 \\
Perizym red & Antiperoxide & 7480 & 2710 \\
Breviol A69 & Dispersant & 1570 & 150 \\
Hydroxy clean & Soap & 670 & 250 \\
Dispersan PNG & Dispersant & 146 & 41 \\
Peristal BFL & Wetting agent & 45 & 9 \\
\hline
\end{tabular}

Table 2

$\mathrm{EC}_{20}$-values $\left(\mathrm{mg} \mathrm{l}^{-1}\right)$ of reactive dyestuffs used in textile finishing industry obtained by bioluminescence test $(15 \mathrm{~min})^{\mathrm{a}}$

\begin{tabular}{lll}
\hline Dyestuffs & Color index & $\mathrm{EC}_{20}$ \\
\hline Procion yellow HEXL & $\mathrm{nn}$ & 220 \\
Procion blue HERD & R.blue 160 & $>610$ \\
Procion yellow H-E4R & R.yellow 84 & 280 \\
Ambifix navy HER & R.blue 171 & 200 \\
Ambifix black BFGR & $\mathrm{nn}$ & 170 \\
Procion navy HEXL & $\mathrm{nn}$ & 140 \\
Remozal black B & R.black 5 & $>125$ \\
Procion deep red HEXL & $\mathrm{nn}$ & $>51$ \\
Procion red H-E3G & $\mathrm{nn}$ & $>46$ \\
Procion red HE3B & R.red 120 & $>46$ \\
Ambifix yellow VRNL & R.yellow 107 & 5 \\
\hline
\end{tabular}

${ }^{\mathrm{a}} \mathrm{nn}-$ not listed on the color index.

than $\mathrm{EC}_{50}$ when there is a solubility problem for the chemicals.

The selected textile finishing mill is a representative example for the knit fabric textile finishing subcategory as it handles cotton, viscose rayon, polyester, polyamide knit fabrics together with cotton/polyester, polyester/ viscose rayon and viscose rayon/cotton knit blends. The plant operation involves 20 different processes, all in batch systems. The process requires an average of $750 \mathrm{~m}^{3}$ of water per day. It houses a wastewater treatment plant, composed of an equalization basin, a neutralization tank and an activated sludge system with a 24 $\mathrm{h}$ hydraulic retention time, providing full treatment to the plant effluents before discharge into an adjacent creek.

The routine analysis of conventional wastewater parameters is necessary in order to monitor the quality of effluents to decide the further reuse or discharge. Tables 3 and 4 show the toxicity and water quality analysis results, such as total organic carbon (TOC) and chemical oxygen demand (COD), of effluents of different production processes in the textile mill in April and June 1999, respectively.

The common dyeing processes at a textile plant vary with the substrate to be finished and with the consumers demand (Lin and Lin, 1993). Results given in the Tables 3 and 4 demonstrate how the quality of process effluents varies with the typical processes and chemicals used. The variation of the composition of the process effluents makes therefore the statement of average values on their toxicity and conventional wastewater characteristics impossible. To simplify the presentation of our data of effluents the toxicity is divided into the following three categories based upon GL-values: (i) high toxicity for samples with a GL-value $>100$; (ii) moderate toxicity $\geqslant 10$ to 100 ; and (iii) low toxicity with a GL-value $<10$. Due to the recipes provided by our industrial partners and information obtained from the safety data sheets, 
Table 3

Conventional parameters and GL-values obtained by bioluminescence test of selected process effluents from a textile finishing plant in Ayazaga, Istanbul, Turkey, April 1999

\begin{tabular}{|c|c|c|c|c|c|}
\hline Processes & $\mathrm{pH}$ & $\begin{array}{l}\text { Conductivity } \\
\left(\mathrm{mS} \mathrm{cm}^{-1}\right)\end{array}$ & $\begin{array}{l}\mathrm{COD} \\
\left(\mathrm{mg}^{-1}\right)\end{array}$ & $\begin{array}{l}\text { TOC } \\
\left(\mathrm{mg} \mathrm{1}^{-1}\right)\end{array}$ & $\begin{array}{l}\text { GL-value } \\
\text { (30 min) }\end{array}$ \\
\hline \multicolumn{6}{|l|}{$95^{\circ} \mathrm{C}$ procion dyeing } \\
\hline Dye bath & 10.3 & 120.1 & 1330 & 661 & 12 \\
\hline \multicolumn{6}{|l|}{ First rinse } \\
\hline After dyeing & 10.5 & 35.4 & 207 & 131 & 6 \\
\hline Soaping & 8.6 & 6.4 & 1064 & 451 & 3 \\
\hline \multicolumn{6}{|l|}{$60^{\circ} \mathrm{C}$ reactive dyeing } \\
\hline Dye bath & 12.0 & 102.0 & 946 & 482 & 32 \\
\hline After dyeing & 11.7 & 31.7 & 241 & 120 & 16 \\
\hline Soaping & 8.7 & 3.8 & 257 & 97 & 12 \\
\hline Equalization basin & 7.5 & 9.5 & 228 & 89 & 6 \\
\hline $\begin{array}{l}\text { Effluent of } \\
\text { treatment plant }\end{array}$ & 8.2 & 12.5 & 105 & 24 & 1 \\
\hline
\end{tabular}

Table 4

Conventional parameters and GL-values obtained by bioluminescence test of selected process effluents from a textile finishing plant in Ayazaga, Istanbul, Turkey, June 1999

\begin{tabular}{|c|c|c|c|c|c|}
\hline Sample & $\mathrm{pH}$ & $\begin{array}{l}\text { Conductivity } \\
\left(\mathrm{mS} \mathrm{cm} \mathrm{cm}^{-1}\right)\end{array}$ & $\begin{array}{l}\text { COD } \\
\left(\mathrm{mg} \mathrm{l}^{-1}\right)\end{array}$ & $\begin{array}{l}\text { TOC } \\
\left(\mathrm{mg} \mathrm{l}^{-1}\right)\end{array}$ & $\begin{array}{l}\text { GL-value } \\
(30 \mathrm{~min})\end{array}$ \\
\hline \multicolumn{6}{|c|}{$95^{\circ} \mathrm{C}$ reactive dyeing with bleaching } \\
\hline Dye bath & 10.6 & 76.1 & 1500 & 206.5 & 6 \\
\hline \multicolumn{6}{|l|}{ First rinse } \\
\hline After dyeing & 10.1 & 6.1 & 80 & 8.7 & 2 \\
\hline Soaping & 9.4 & 3.5 & 50 & 11.6 & 2 \\
\hline \multicolumn{6}{|l|}{ Last rinse } \\
\hline After soaping & 8.5 & 1.5 & 35 & 6.9 & 2 \\
\hline Softening & 7.6 & 1.2 & 440 & 60.1 & 3 \\
\hline Raw composite & 10.0 & 19.6 & 1125 & 183.5 & 24 \\
\hline Reuse composite & 2.0 & 1.6 & 350 & 26.6 & 3 \\
\hline Retentant & 10.0 & 17.9 & 1485 & 162.0 & 100 \\
\hline \multicolumn{6}{|l|}{10 min ozonation } \\
\hline Effluent & 4.8 & 13.3 & 93 & 157.0 & 16 \\
\hline
\end{tabular}

provided by the producers such as BASF, ICI Colors and Fine Chemicals, Thai AMBICA Chemicals, all dyestuffs and chemicals used should not have such an inhibitory effect on the bacterial activity. As it is known, the manufacturer of dyes, auxiliaries, etc., is asked by the legislation to provide information via material safety data sheet on the products physical, chemical characteristics. The safety data sheets have also to contain toxicological-, ecological-data such as $\mathrm{LD}_{50}$ for fish or rat but they seldom provide information on inhibition of bacterial activity.

Among the 17 effluent samples investigated, one exhibited high toxicity, seven samples showed moderate toxicity, and nine had low or no toxicity at all (Tables 3 and 4). Dye bath effluents indicating their high complexity (Table 3) as a mixture of auxiliaries, salts, surfactants, degradation products and unknown com- ponents of refractory pollutants showed higher toxicity than the following rinsing water effluents as expected. The high toxicity to the luminescent bacteria could be explained as a result of some unknown products produced during the dyeing processes.

Due to the huge amounts of water used during the dyeing and finishing processes the textile dyeing and finishing industry is interested to find methods to minimize the water and wastewater volume and related costs. The reuse of less polluted process effluents, e.g., effluents of rinsing processes, decrease costs but increase the probability of acute toxicity to the microflora of wastewater treatment units. Bioluminescence test could be an alternative as a rapid and cost-effective method to protect the biologically based stages in sewage treatment facilities (Bulich, 1979; Nohava and Vogel, 1995). In this study we observed high aquatic toxicity potential of 
samples, collected in June 1999, described as "raw composite", a mixture of five selected process effluents, and "remaining composite", a mixture of process effluents after removing the reusable process water (last rinse after soaping + softening), (Table 4) to the mills own wastewater treatment plant or to the microflora of a receiving water body.

\section{Conclusions}

Based upon the results, following conclusions can be given: (i) the (Microtox assay) bioluminescence test could be applied as a rapid pre-screening test for toxicity evaluation of different process effluents; (ii) the most toxic auxiliary to $V$. fischeri was Peristal BFL; (iii) the most toxic azo dye was Ambifix yellow VRNL, and the least toxic one was Procion blue HERD; (iv) the $30 \mathrm{~min}$ GL-value of the effluents of different processes differed significantly depending upon the finishing process.

Due to the scarce information on the toxic effect of auxiliaries as well as different process effluents and little standardization - no norms, ring tests and very less toxicity data - it is difficult to judge the quality of obtained results. We are also aware of the limitations concerning handling and data interpretation for colored water samples, nevertheless, the bioluminescence test can be used as a pre-toxicity screening test to obtain information on overall toxicity of different samples and chemicals from textile dyeing and finishing industry. It is also important to point out that further investigations are necessary to gain information on the synergistic effect of auxiliaries and their degradation products. In this aspect our findings can be seen as a first contribution to this subject and as an achievement towards cleaner technology since the use of Microtox assay simplifies the decision to substitute the toxic chemicals towards nontoxic one.

\section{Acknowledgements}

This work was supported by Volkswagen-Foundation (II/72 146), by The German Ministry of Science, Education and Technology (BMBF), by The National Natural Science Foundation of China (Grant 29637010) and by The Research Center for Eco-Environmental Sciences (RCEES-KIP-9901). We wish to thank the staff at the textile mill in Istanbul for their valuable help.

\section{References}

Asami, M., Suzuki, N., Nakanishi, J., 1996. Aquatic toxicity emission from Tokyo: wastewater measured using marine luminescent bacterium, Photobacterium phosphoreum. Water Sci. Tech. 33, 121-128.

Backhaus, T., Froehner, K., Altenburger, R., Grimme, L.H., 1997. Toxicity testing with Vibrio fischeri: a comparison between the long term $(24 \mathrm{~h})$ and the short term $(30 \mathrm{~min})$ bioassay. Chemosphere 35, 2925-2938.

Beydilli, M.I., Pavlostathis, S.G., Tincher, W.C., 1998. Decolorization and toxicity screening of selected reactive azo dyes under methanogenic condition. Water Sci. Tech. 38, 225232.

Bulich, A.A., 1979. Use of luminescent bacteria for determining toxicity in aquatic environment. In: Markings, L.L., Kimerle, R.A. (Eds.), Aquatic Toxicity, STP 667. American Society for Testing and Materials, PA, USA, pp. 98-106.

Dodard, S.D., Renoux, A.Y., Hawari, J., Ampleman, G., Thiboutot, S., Sunahara, G.I., 1999. Ecotoxicity characterization of dinitrotoluenes and some of their reduced metabolites. Chemosphere 38, 2071-2079.

Dombroski, E.C., Gaudet, I.D., Florence, L.Z., Qureshi, A.A., 1996. A comparison of techniques used to extract solid samples prior to acute toxicity analysis using the Microtox test. Environ. Toxicol. Water Qual. Int. J. 11, 121-128.

Devare, M., Bahadir, M., 1994. Biological monitoring of landfill leachate using plants and luminescent bacteria. Chemosphere 28, 261-271.

Froehner, K., Backhaus, T., Grimme, L.H., 2000. Bioassays with Vibrio fischeri for the assessment of delayed toxicity. Chemosphere 40, 821-828.

Galli, R., Munz, C.D., Scholtz, R., 1994. Evaluation and application of aquatic toxicity tests: use of Microtox test for the prediction of toxicity based upon concentrations of contaminants in soil. Hydrobiologia 273, 173-189.

Ince, M.A., 1999. Personal communication.

Kahru, A., Tomson, K., Pall, T., et al., 1996. Study of toxicity of pesticides using luminescent bacteria Photobacterium phosphoreum. Water Sci. Tech. 33, 147-154.

Lin, S.H, Lin, C.M., 1993. Treatment of textile waste effluents by ozonation and chemical coagulation. Water Res. 27, 1743-1748.

Lopez, A., Ricco, G., Mascolo, G., Tiravanti, G., Di Pinto, A.C., Passino, R., 1998. Biodegradability enhancement of refractory pollutants by ozonation: a laboratory investigation on an azo-dyes intermediate. Water Sci. Tech. 38, 239245.

Nohava, M., Vogel, W.R., 1995. Evaluation of the luminescent bacteria bioassay for the estimation of the toxicological potential of effluent water samples - Comparison with data from chemical analysis. Environ. Int. 21, 33-37.

Paker, L., 1999. Personal communication.

Spadaro, J.T., Isabelle, L., Renganathan, V., 1994. Hydroxyl radical mediated degradation of azo dyes: evidence for benzene generation. Environ. Sci. Tech. 28, 1389-1393.

Zissi, U., Lyberatos, G., 1996. Azo-dye biodegradation under anoxic conditions. Water Sci. Tech. 34, 495-500.

Ayfer Yediler is a senior scientist at GSF-Institute of Ecological Chemistry. She is coordinator of numerous international (China, Turkey; Romania) projects since 1987. Her academic experiences are: heavy metals and organic chemicals in the environment; eco-toxicological tests; monitoring of hazardous chemicals in maternal breast milk, in hair samples; conservation of endangered species; constructed wetlands in water pollution 
control; clean technology. She is currently working on (i) identification and assessment of the environmental impacts of wastewaters from the selected textile industries, (ii) on ecotoxicological evaluation of reactive azo dyes, and (iii) identification of their toxic intermediates after short-term oxidative treatment.

Chunxia Wang is a associate professor and at present the vice director of the State Key Laboratory of Aquatic Environmental Chemistry, Research Center for Eco-Environmental Sciences, Chinese Academy of Sciences, Beijing. She is coordinator of international cooperations and projects. Her academic experiences are: (1) Environmental behavior of humic substances and their role in Kaschin-Beck disease; (2) The interaction between free radicals, humic substances and collagens; (3) Environmental behavior and eco-toxicological effects of rare earth ele- ments; (4) Separation and purification of human placental estradiol 17-dehydrogenase and its photo-affinitive reaction with triazo-compounds. She is currently working on the fate of heavy metals and organic chemicals in the environment; ecotoxicological assessment of organic contaminants in water and sediment comparing different assays such as biomarkers of mixed function oxygenase, neutral red cytotoxicity and bioluminescence test.

Doris Lienert is a senior scientist with experiences in the analysis of organic chemicals (surfactants, PAHs) in different environmental matrices, extraction and identification of substances in pharmaceutically used plants, recent works on wastewaters of textile industry with the purpose of enhancing the biodegrability of their organic pollutants and the eco-toxicological assessment of the wastewaters. 